\title{
Investigating the Iron-Making Process through the Scientific Analysis of By-products Obtained during Iron-Making from Songdu-ri Site in Jincheon, Korea
}

\author{
Da Yeon Jung, Nam Chul Cho* \\ Department of Cultural Heritage Conservation Science, Kongju National University, Gongju 32588, Korea
}

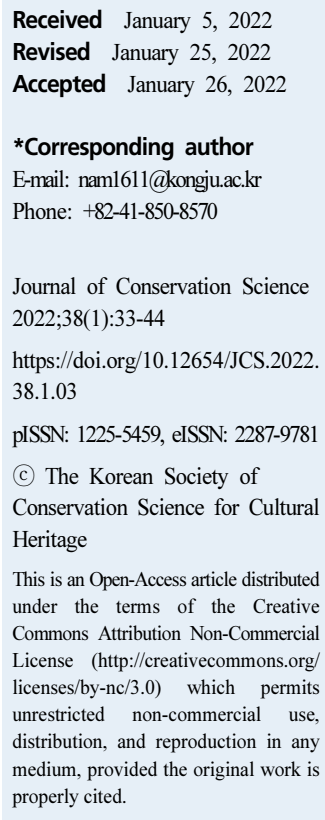

ABSTRACT The study, iron-making process was examined through the scientific analysis of six by-products that were obtained during iron making at the Songdu-ri site in Jincheon. The total Fe content of the slags excavated from the Songdu-ri site was 36.29-54.61 wt $\%$, whereas the deoxidation agent was 26.48-49.08 wt\%. The compound analysis result indicated that fayalite and wüstite are the main compounds in slag. Furthermore, the microstructure analysis result confirmed the presence of fayalite and wüstite in the slag. It can be inferred from the flat shape in a bright matrix structure of the hammer scales that forging was performed in the latter stage. The Raman micro-spectroscopy results confirmed that the surface was hematite $\left(\mathrm{Fe}_{2} \mathrm{O}_{4}\right)$, middle layer was magnetite $\left(\mathrm{Fe}_{3} \mathrm{O}_{4}\right)$, and inner layer was wüstite $(\mathrm{FeO})$. The presence of smelting and smithing slags, spheroid hammer scales, and flake hammer scales suggests that at the Songdu-ri site, iron-making process is carried out by division of labor into producing iron bloom through direct smelting, refining and forge welding, and ingot production.

Key Words Slag, Hammer scales, Direct smelting, Iron-making process

\section{INTRODUCTION}

The human society has developed and advanced significantly owing to the production of iron and iron tools, such as farming tools and weapons. In addition, this has accelerated the division of labor among social classes and larger political systems have emerged, which has laid the foundation for the establishment of ancient states (Jungwon National Research Institute of Cultural Heritage, 2014). Iron artifacts seldom remain in their original shape because iron undergoes corrosion. Therefore, it is extremely difficult to understand the development process of iron culture through excavated iron artifacts (Cho et al., 2013). In general, iron ores, which remain after iron production, or slags, which are generated during the smelting process, are often excavated from iron-making historic sites (Rho, 2000).

Slags refer to remnants generated when irons are smelted or processed from ores (Yoon, 1986). Slag analysis can help us understand the performance of iron-making process in sites and can indicate the character of sites. Therefore, analysis of slags obtained from iron-making sites is crucial, as it can help significantly in understanding the iron-making process of sites (Jungwon National Research Institute of Cultural Heritage, 2014). Iron making requires a comprehensive process from mining to production. Research on iron making requires extensive knowledge and experience, including rich knowledge and experience about metal analysis and understanding of advanced equipment, as well as archaeological knowledge (Choi, 2003).

Iron-making process starts with mining for acquiring 
high-quality raw materials. Smelting is a process for separating iron by reducing iron ores in natural state, and there are two types of smelting: direct and indirect smelting. Iron oxides can be reduced at approximately $800^{\circ} \mathrm{C}$, which is much lower than the melting point of iron, $1535^{\circ} \mathrm{C}$ (Cho, 2015). Since iron ores contain gangue components such as silica and alumina, these components must be separated as slags for successful smelting. To this end, the temperature of $1150 \sim 1350^{\circ} \mathrm{C}$ must be maintained, because at this temperature range, a sufficient amount of monoxide for reduction can be held; however, this is an extremely challenging task for the early smelting work (Cho, 2015). Smithing technique is used for making iron products by forging iron lumps that have undergone smelting process. Smithing is classified by the smithing function or process into refining-smithing and tempering-smithing (Bae, 2018). In fact, refining-smithing and tempering-smithing are hardly distinguishable by the furnace structure or excavated artifacts; they can be only distinguished by analyzing the excavated slags or iron lumps (Rho, 2000). Finally, steel making is a process of carburizing or decarburizing soft iron or pig iron, followed by adjusting and enhancing it into steel (National Museum of Korea, 2017).

The Jungwon region plays a crucial role in Korea's iron-making research, which can be found through historical background and the iron-making sites that have been investigated in this region. The Jungwon region possessed the advantage of a transportation center that had to be occupied for the power expansion of three kingdoms, as well as rich iron production areas and distribution network. Therefore, there are many iron-making sites of Baekje, which aimed to expand the national power by using the abundant iron in this area from the early days, such as Chilgeum-dong sites, Tangeumdae Fortress, and Tappyeong-ri sites in Chungju, where iron was produced, distributed, and even underwent secondary processing using the Namhan River, as well as the iron production site in Seokjang-ri, Jincheon, which was operated during the Baekje Dynasty. During the Goryeo Dynasty, "Daincheolso," where a special artesian group gathered to produce iron, was operated in Chungju at the national level (Jungwon National Research Institute of Cultural Heritage, 2014). Furthermore, historical records from the Joseon Dynasty mentioned iron as the first of the local products of the Chungju region and introduced various iron-producing areas in the Jungwon region (Jungwon National Research Institute of Cultural Heritage, 2014).

Jincheon is one of the representative areas with iron-making sites, including Chungju, Cheongwon, and Cheongju. This study analyzes by-products obtained during iron-making process from the Songdu-ri site in Jincheon to investigate the iron-making process through a scientific analysis of six iron-making samples including slags, flake hammer scales, and spheroid hammer scale excavated from the Songdu-ri site in Jincheon.

\section{OVERVIEW OF SITES}

Various types of sites from the Bronze Age to the Joseon Dynasty were investigated at the Songdu-ri site through a sample survey in 2016 and excavation surveys in 2017 and 2018. The excavation surveys reported 56 iron wares in total, including smelting and smithing hearths. Based on the shapes of the nearby earthenware kilns and the chronology of excavated sites, it was assumed that these iron wares were operated by a local group in Jincheon that existed before Baekje (Central Institute of Cultural Heritage, 2020).

The Songdu-ri site is located around a large alluvial plain spread between low gentle hills developed between the Miho stream and the Baekgok stream. The iron wares were found at locations 1-2, 1-4, 2-1, 3-5, 4-1, 7-2, and 7-3, where the end of the hill is joined with the alluvial plain. This area has somewhat complex terrains because several old channels run toward the stream, and most of the iron wares are distributed around the old channels (Figure 1).

The furnace at location 1 was formed around a smithing hearth, rather than a smelting hearth. Location 3 is divided into five sub-locations around the top of the hill that stretches from north to south, and smelting and smithing hearths were found here. The smelting hearths are distributed around the end of the slope, whereas the smithing hearths are distributed sporadically to rather the middle of the slope. Therefore, it is estimated that smithing hearths had fewer locational limits than the smelting hearths. Since various iron wares, including smelting and smithing hearths, are distributed, they are considered as important materials that show the characteristics of the iron production technology at that time. Earthenware kilns and furnaces were identified at location 4, along with living sites such as building sites, residential sites, 




Figure 1. Lay out of iron production Songdu-ri site, Jincheon.

pit features, water collecting facilities, pit groups, and spherical features. However, it is likely that the residential and production spaces were separated because residential sites are concentrated in the northern valley of location 4 , whereas furnaces are concentrated in the southern ravine. In particular, smelting and smithing hearths are gathered together in the southern ravine, and pit groups, spherical features, and building sites are located around them. Thus, it can be considered a landscape where production facilities, related workshops, and auxiliary facilities are present. Such a distribution pattern of iron wares contrasts with locations 1-3. It has been interpreted that iron wares were first built at location 4 , and the smelting, refining and smithing processes were performed at one place; thereafter, the refining and smithing processes moved toward locations 1-3 on the outskirts of the village due to the division of labor.

Among the furnaces in the sites, smelting hearths with clear structural features that had a tapping hole with a diameter of $110 \sim 140 \mathrm{~cm}$ and small furnaces with a diameter of $30 \sim 80 \mathrm{~cm}$ were observed together. Among these small furnaces, spheroid hammer scale or flake hammer scale were found in furnace no. 2 at location 1-2, furnace no. 3 at location 1-4, and furnace no. 3 at location 2-1. They suggest that the smithing was performed mainly in small furnaces (Central Institute of Cultural Heritage, 2020). The furnaces no. 1 and no. 2 at location 1-2 and furnace no. 3 at location $1-4$, where by-products, which are the target of this study, were found, were refining and smithing hearths, respectively, whereas the furnace no. 13 at location 3-5 and furnace no. 1 at location 4-1 were smelting hearths.

\section{SAMPLES AND ANALYSIS METHOD}

\subsection{Samples}

Herein, four slags, one spheroid hammer scale, and one flake hammer scale, which were excavated from the Songdu-ri site in Jincheon and are closely sited to the iron-making process, were selected as the samples for analysis (Table 1, Figure 2). 
Table 1. List of by-products excavated from iron smelting Songdu-ri site, Jincheon

\begin{tabular}{clc}
\hline No. & \multicolumn{1}{c}{ Findspot } & Name \\
\hline 1 & Locality $1-2$ no. 1 furnace & Slag \\
\hline 2 & Locality $1-2$ no. 2 furnace & Spheroid hammer scale \\
\hline 3 & Locality $1-4$ no. 3 furnace & Slag \\
\hline 4 & Locality $3-5$ no. 13 furnace & Slag \\
\hline 5 & Locality $4-1$ no. 14 furnace & Slag \\
\hline 6 & Locality $4-1$ no. 46 residential area & \\
\hline
\end{tabular}
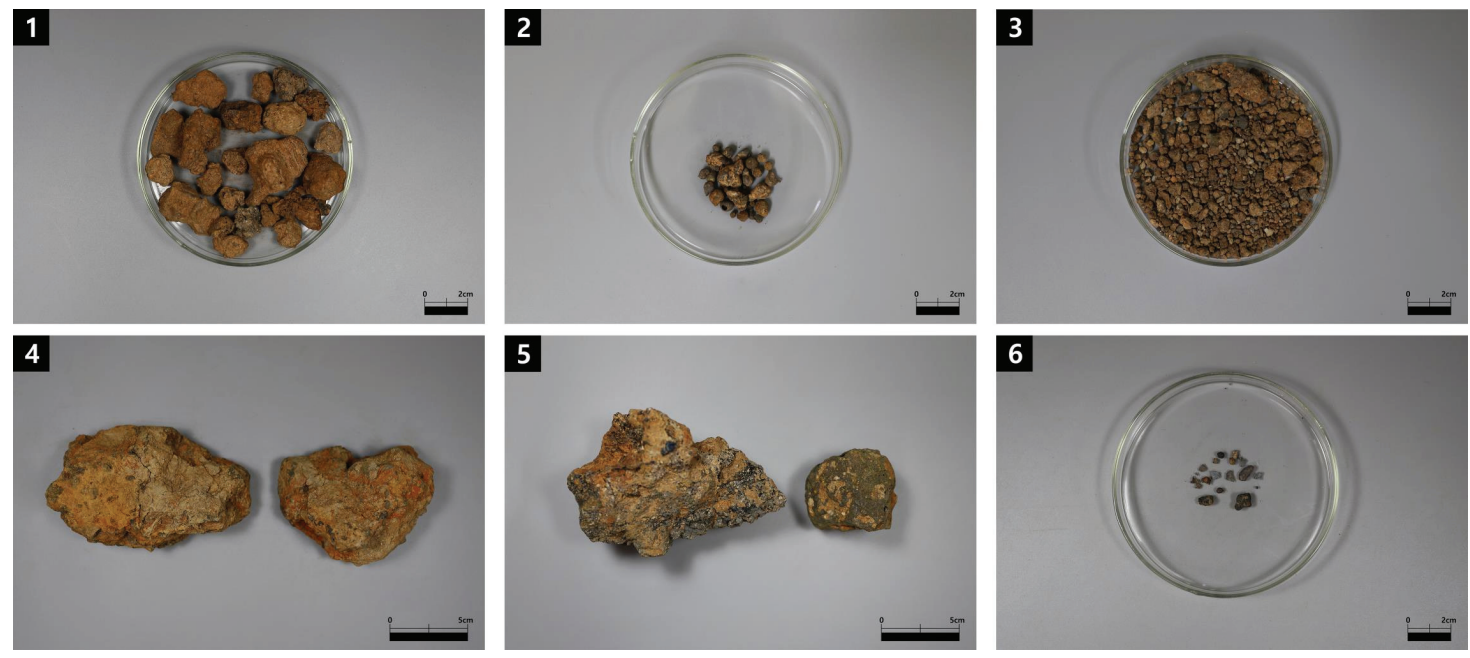

Figure 2. By-products excavated from iron smelting Songdu-ri site, Jincheon.

\subsection{Analysis method}

The samples were crushed to appropriate sizes before analysis. Then, after immersing the samples in ethyl alcohol, foreign substances were removed from the surface using an ultrasonic cleaner and then dried. Principal component analysis and compound analysis were performed only for slag samples, which had a sufficient quantity, because the quantities of other samples were not sufficient.

\subsubsection{Principal component analysis}

After the samples were dried and pulverized, the principal components were analyzed using wavelength dispersive X-ray fluorescence spectroscopy (WD-XRF, S8 Tiger, Bruker, DEU). The analysis results were obtained and investigated by semi-quantitative analysis.

\subsubsection{Compound analysis}

The samples were pulverized, and X-ray diffraction (X-ray
Diffraction System (XRD), X'pertPRO MPD, Philips, NLD) was performed to examine the conditions of compounds. The $2 \theta$ value was $3-70^{\circ}$, scan speed was $0.5 \mathrm{~s} / \mathrm{step}$, step size was $0.02^{\circ}$, voltage was $40 \mathrm{kV}$, and current was $40 \mathrm{~mA}$. Copper was used as the target for analysis.

\subsubsection{Microstructure analysis}

The samples were mounted with epoxy resin to observe the microstructures of slag, flake hammer scale, spheroid hammer scale. The mounted samples were ground from 100 to 4000 mesh, and then fine grinding was performed using 3 and $1 \mu \mathrm{m}$ (DP-Spray, Struers, DNK). The microstructures of the samples were observed with a metal microscope (DM $2500 \mathrm{M}$, Leica, DEU), and the detailed microstructures were observed with a scanning electron microscope (SEM, MIRA3, Tescan, CZE). The chemical compositions of microstructures were then analyzed using an energy dispersive spectrometer (EDS, QUANTAX200, Bruker, 
Table 2. Chemical composition of by-products excavated from iron smelting Songdu-ri site, Jincheon

\begin{tabular}{|c|c|c|c|c|c|c|c|c|c|c|c|c|}
\hline \multirow{2}{*}{ No. } & \multicolumn{12}{|c|}{ Major composition (wt\%) } \\
\hline & $\mathrm{FeO}$ & $\mathrm{SiO}_{2}$ & $\mathrm{Al}_{2} \mathrm{O}_{3}$ & $\mathrm{CaO}$ & $\mathrm{K}_{2} \mathrm{O}$ & $\mathrm{P}_{2} \mathrm{O}_{5}$ & $\mathrm{MgO}$ & $\mathrm{TiO}_{2}$ & $\mathrm{Na}_{2} \mathrm{O}$ & $\mathrm{MnO}$ & $\mathrm{T} \cdot \mathrm{Fe}$ & Deoxidation agent \\
\hline 1 & 46.78 & 33.19 & 8.54 & 6.69 & 2.32 & 0.98 & 0.75 & 0.33 & 0.24 & 0.17 & 36.29 & 49.08 \\
\hline 3 & 68.18 & 18.35 & 6.31 & 1.42 & 0.89 & 4.02 & 0.45 & 0.22 & 0.00 & 0.15 & 52.87 & 26.48 \\
\hline 4 & 70.37 & 22.37 & 3.47 & 1.46 & 1.10 & 0.53 & 0.27 & 0.15 & 0.22 & 0.06 & 54.61 & 27.52 \\
\hline 5 & 70.76 & 23.19 & 2.38 & 1.44 & 0.76 & 0.65 & 0.19 & 0.19 & 0.35 & 0.09 & 55.00 & 27.20 \\
\hline
\end{tabular}

DEU). The samples were coated with Pt to increase the conductivity of samples and minimize the effect on the composition ratio.

\subsubsection{Raman micro-spectroscopy}

Raman micro-spectroscopy (Ar-ion Laser 514.5 nm, LabRam Aramis, Horiba Jobin Yvon, FRA) was performed for the accurate identification of microstructures. For Raman micro-spectroscopy, the Pt coating used for microstructure analysis before was removed, and then the analysis was performed without pretreatment.

\section{ANALYSIS RESULTS}

\subsection{Principal component analysis}

$\mathrm{XRF}$ analysis was performed to examine the principal components of the slags excavated from the Songdu-ri site in Jincheon, and the results are summarized in Table 2. Among the principal components of slags, the total $\mathrm{Fe}$ content suggests the iron content remaining in the slag; a smaller total $\mathrm{Fe}$ content indicates a higher iron recovery rate (Yoon, 1986). The deoxidation agent $\left(\mathrm{SiO}_{2}+\mathrm{Al}_{2} \mathrm{O}_{3}+\mathrm{CaO}\right.$ $+\mathrm{MgO}$ ) added during smelting facilitates the smelting by lowering the melting point and its content tends to be inversely proportional to the total $\mathrm{Fe}$ content.

Ancient iron-making processes include direct and indirect smelting. The total Fe content and deoxidation agent content, according to the classification of direct and indirect smelting based on the analysis of domestic iron-making sites, are shown in Figure 3. The slag analysis at the Songdu-ri site in Jincheon suggests that the average total $\mathrm{Fe}$ content was $49.69 \mathrm{wt} \%$ and the slag deoxidation agent content was 32.57 wt\%. As shown in Figure 3, the total Fe contents of direct and indirect melting were $18.07 \sim 49.34 \mathrm{wt} \%$ and $3.65 \sim$ $11.95 \mathrm{wt} \%$, respectively. Furthermore, the deoxidation agent contents of direct and indirect melting were 30.10 69.14 wt $\%$ and $78.33 \sim 88.55 \mathrm{wt} \%$, respectively. This shows that the total Fe content and slag former content of the Songdu-ri site are similar to those of direct smelting.
Total Fe

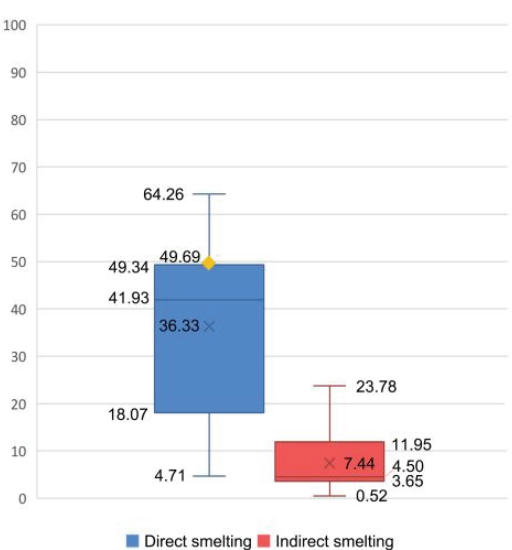

Deoxidation agent

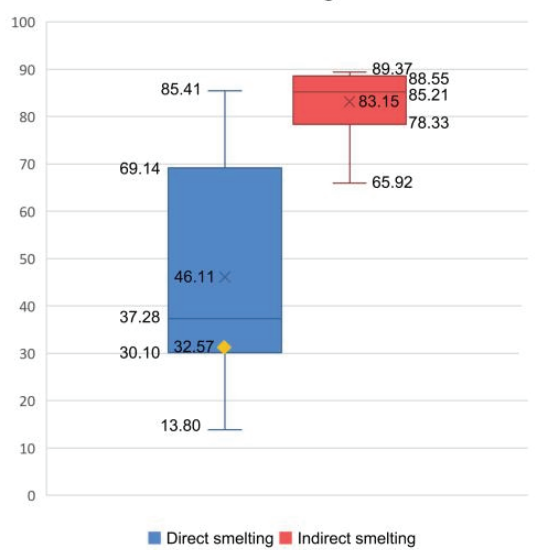

Figure 3. Total $\mathrm{Fe}$ and Deoxidation agent by smelting. 
A

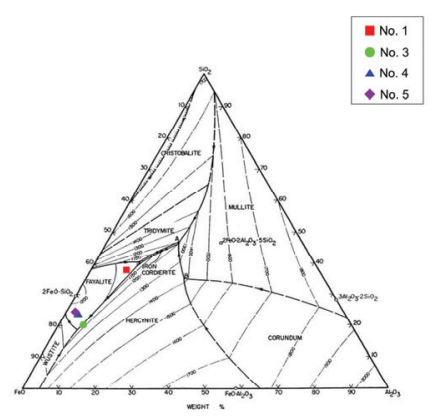

Figure 4. (A) $\mathrm{FeO}-\mathrm{Al}_{2} \mathrm{O}_{3}-\mathrm{SiO}_{2}$ phase diagrams.

The working temperature inside the furnace can be estimated by substituting the analyzed data in the $\mathrm{FeO}-\mathrm{Al}_{2} \mathrm{O}_{3}-\mathrm{SiO}_{2}$ (FAS) phase diagram or the $\mathrm{FeO}-\mathrm{CaO}-\mathrm{SiO}_{2}$ (FCS) phase diagram. For non-metal oxides, three oxides were standardized to $100 \%$ and substituted. The result of estimating the extrusion temperature using the FAS and FCS phase diagram confirmed that the temperature was mainly around $1200^{\circ} \mathrm{C}$ (Figure 4). Direct smelting required a high temperature of $1539^{\circ} \mathrm{C}$ to obtain pure iron; however, in ancient times, it was difficult to achieve such a high temperature only by charcoal fuel and natural ventilation (Lee, 2017). Therefore, direct smelting enables iron production by reducing ores at temperatures below $1200^{\circ} \mathrm{C}$ (Rho, 2000). The method of reducing iron at high
B

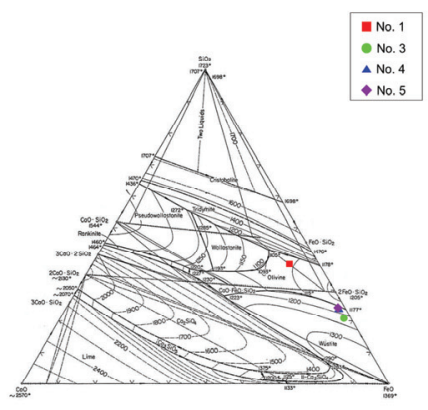

(B) $\mathrm{FeO}-\mathrm{CaO}-\mathrm{SiO}_{2}$ phase diagrams.

temperature of above $1200^{\circ} \mathrm{C}$ using a furnace is called Indirect smelting (Bae and Cho, 2020). By completely melting the raw material, iron and slag are sufficiently separated, resulting in mostly glassy slag (Lee et al., 2018; Bae and Cho, 2020). The total Fe content, slag former content, and extrusion temperature of the iron-making by-products obtained from the Songdu-ri site indicated that iron was produced at temperatures around $1200^{\circ} \mathrm{C}$.

\subsection{Compound analysis}

$\mathrm{XRD}$ analysis was performed to examine the compound states of the by-products obtained from the Songdu-ri site; the results are shown in Figure 5.

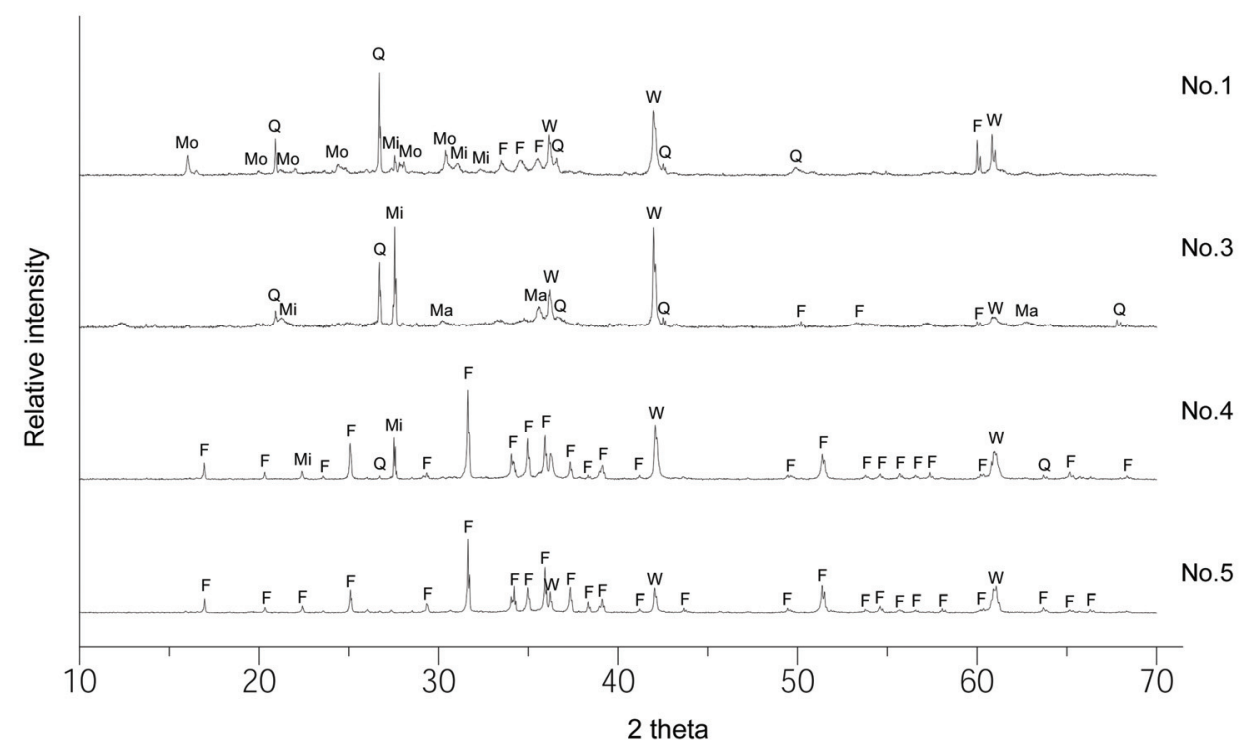

Figure 5. X-ray diffraction patterns of by-products excavated from iron smelting Songdu-ri site, Jincheon (F: Fayalite, Ma: Magnetite, Mi: Microcline, Mo: Monticellite, Q: Quartz, W: Wüstite). 
The analysis result suggests that fayalite and wüstite were detected as main compounds of the slag, and quartz, magnetite, microcline, and monticellite were identified in some samples. The smithing slags excavated from smithing sites are characterized by the coexistence of fayalite and wüstite, as well as the appearance of well-grown wüstite form in high quantities. Furthermore, the smelting slags are characterized by the detection of fayalite as a main phase, which sometimes coexist with a glassy material, or the detection of wüstite (Yoon, 1986). In No. 1 and 3, fayalite and wüstite coexisted and spheroid hammer scale and flake hammer scale were identified at the excavated locations, thus confirming that the slags were formed by smithing work. Furthermore, at No. 4 and 5, the detection of fayalite as a main phase and identification of wüstite in some samples suggest that the slag was produced from a smelting process.

\subsection{Microstructure observation result}

By-products, the subject of this study, were observed with a metal microscope. In addition, the detailed microstructures were observed and composition was examined by performing
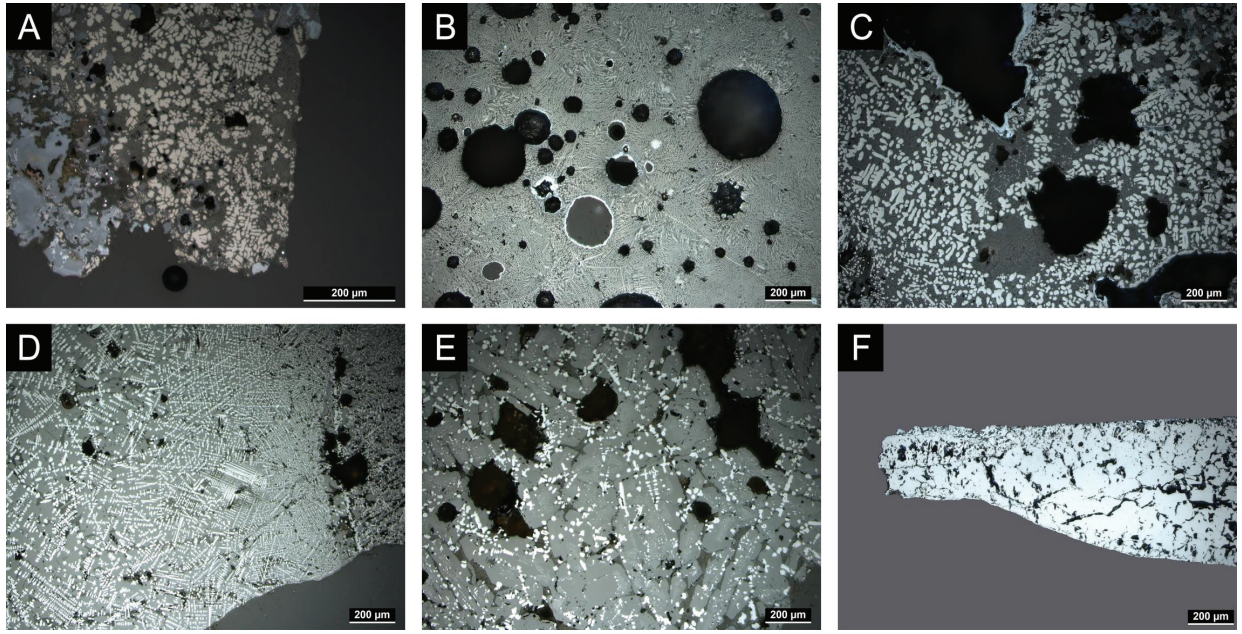

Figure 6. Image of metallurgical microscope from by-products (A to F).
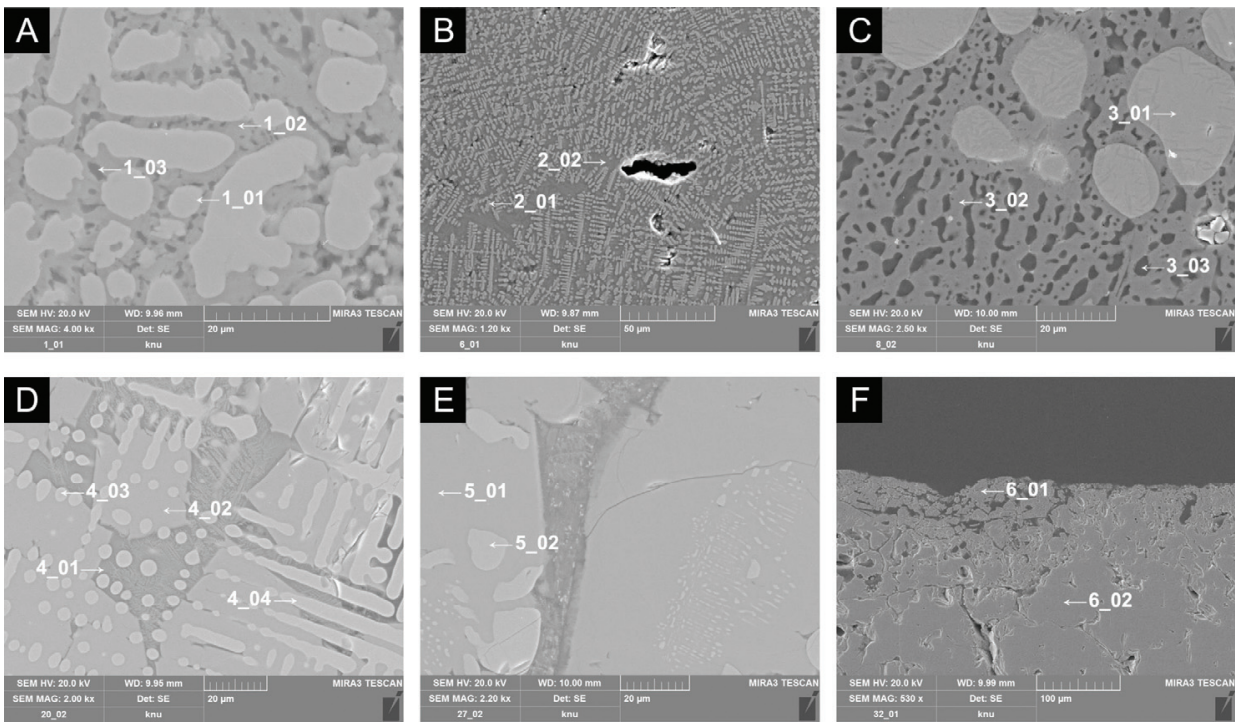

Figure 7. SEM image and points of EDS analysis from by-products (A to F). 
SEM-EDS analysis (Figures 6 and 7).

In No. 1 (slag), a blackened area is observed due to the progress of corrosion, and white elliptical shape (絹狀) are observed on gray-white microstructure (Figure 6A). The SEM-EDS analysis result (Table 3, Figure 7A) confirmed that the white elliptical shape (1_01) is wüstite with a high $\mathrm{FeO}$ content. The white elliptical shape with a high $\mathrm{FeO}$ content has been identified as wüstite by Raman micro-spectroscopy (Kwon, 2016).

Hence, the white elliptical shape with a high FeO content is wüstite. 1_02 is a grayish white microstructure with high contents of $\mathrm{FeO}$ and $\mathrm{SiO}_{2}$, and between them, 1_03 glassy background is observed, whose principal components are $\mathrm{K}_{2} \mathrm{O}$ and $\mathrm{Al}_{2} \mathrm{O}_{3}$. The grayish white long columnar microstructure with high contents of $\mathrm{FeO}$ and $\mathrm{SiO}_{2}$ has been identified as fayalite by Raman micro-spectroscopy (Kwon, 2016). Thus, the grayish white microstructures with the $\mathrm{FeO}$ and $\mathrm{SiO}_{2}$ contents of $62.56 \mathrm{wt} \%$ and $22.56 \mathrm{wt} \%$, respectively, are fayalite.

No. 2 is a spheroid hammer scale excavated from no. 2 furnace at location 1-2. The spheroid hammer scale is an iron material formed by melting and flowing off surface substances, such as impurities, when an iron material in the smithing process is put into a furnace and heated (Jungwon National Research Institute of Cultural Heritage, 2016). As a result of metal microscope observation, large and small pores were scattered throughout the material and an oxide layer was observed on the outer edge surface (Figure 6B). In addition, a gray background and dense growth of white dendritic microstructures could be observed inside. SEM-EDS was performed to observe enlarged white microstructure (Table 3, Figure 7B). 2_01 was identified as a white dendritic wüstite with a high $\mathrm{FeO}$ content, and 2_02 was identified as a glassy background, wherein $\mathrm{SiO}_{2}$ and $\mathrm{FeO}$ appeared as principal components.

As for No. 3 (slag), the outer microstructure was covered with an oxide layer; a gray layer was observed in the inner microstructure on the background, and a white elliptical shaped microstructure was observed (Figure 6C). As a result of the SEM-EDS analysis (Table 3, Figure 7C), 3_01 was identified with white shoulder shaped wüstite containing $100.00 \mathrm{wt} \% \mathrm{FeO}$. In addition, 3_02 was identified as fayalite with $\mathrm{FeO}$ and $\mathrm{SiO}_{2}$ contents of $51.72 \mathrm{wt} \%$ and $24.11 \mathrm{wt} \%$, respectively. Moreover, 3_03 was identified as a glassy background wherein $\mathrm{Al}_{2} \mathrm{O}_{3}$ and $\mathrm{K}_{2} \mathrm{O}$ appeared as principal components.

Table 3. EDS analysis results of by-products

\begin{tabular}{|c|c|c|c|c|c|c|}
\hline \multirow{2}{*}{ Analysis position } & \multicolumn{6}{|c|}{ Composition (wt\%) } \\
\hline & $\mathrm{FeO}$ & $\mathrm{SiO}_{2}$ & $\mathrm{CaO}$ & $\mathrm{Al}_{2} \mathrm{O}_{3}$ & $\mathrm{~K}_{2} \mathrm{O}$ & $\mathrm{MgO}$ \\
\hline 1_01 & 100.00 & - & - & - & - & - \\
\hline 1_02 & 62.56 & 22.56 & 13.43 & - & 0.39 & 1.06 \\
\hline 1_03 & 29.18 & 39.45 & 6.47 & 11.32 & 13.57 & - \\
\hline 2_01 & 94.63 & 2.60 & 2.05 & 0.72 & - & - \\
\hline $2 \_02$ & 45.65 & 29.38 & 12.56 & 6.94 & 4.14 & 1.32 \\
\hline 3_01 & 100.00 & - & - & - & - & - \\
\hline 3_02 & 51.72 & 24.11 & 22.55 & 0.33 & 0.43 & 0.86 \\
\hline 3_03 & 7.13 & 48.61 & 2.09 & 21.25 & 20.91 & - \\
\hline 4_01 & 34.60 & 34.80 & 8.38 & 13.29 & 8.92 & - \\
\hline 4_02 & 73.50 & 24.00 & 2.51 & - & - & - \\
\hline 4_03 & 100.00 & - & - & - & - & - \\
\hline 4_04 & 98.52 & 0.77 & - & 0.71 & - & - \\
\hline 5_01 & 71.77 & 27.09 & 1.14 & - & - & - \\
\hline 5_02 & 100.00 & - & - & - & - & - \\
\hline 6_01 & 98.54 & - & 1.46 & - & - & - \\
\hline 6_02 & 100.00 & - & - & - & - & - \\
\hline
\end{tabular}


In No. 4 (slag), it can be observed that white dendritic microstructures have grown on grayish white long columnar microstructures (Figure 6D). SEM-EDS analysis was conducted to observe the detailed microstructures of slags and investigate their compositions (Table 3, Figure 7D). 4_01 was identified as a glassy background with $\mathrm{Al}_{2} \mathrm{O}_{3}$ and $\mathrm{K}_{2} \mathrm{O}$ appearing as principal components; 4_02 was identified as fayalite with $\mathrm{FeO}$ and $\mathrm{SiO}_{2}$ contents of $73.50 \mathrm{wt} \%$ and 24.00 $\mathrm{wt} \%$, respectively; furthermore, 4_03 and 4_04 were identified as white wüstite.

As a result of metal microscope observation for No. 5 (slag), a white elliptical shaped microstructure on a gray microstructure was observed (Figure 6E). As a result of the SEM-EDS analysis (Table 3, Figure 7E), 5_01 was identified as fayalite with $\mathrm{FeO}$ and $\mathrm{SiO}_{2}$ contents of $71.77 \mathrm{wt} \%$ and $27.09 \mathrm{wt} \%$, respectively, whereas 5_02 was identified as a white elliptical shaped wüstite with $100.00 \mathrm{wt} \% \mathrm{FeO}$.

No. 6 is a flake hammer scale excavated from no. 46 residential site at location 4-1. Flake hammer scale is a thin flake with a thickness of around $1 \mathrm{~mm}$, which is peeled off during hammering in the smithing process. Moreover, it has strong magnetic property and is a criterion for smithing work
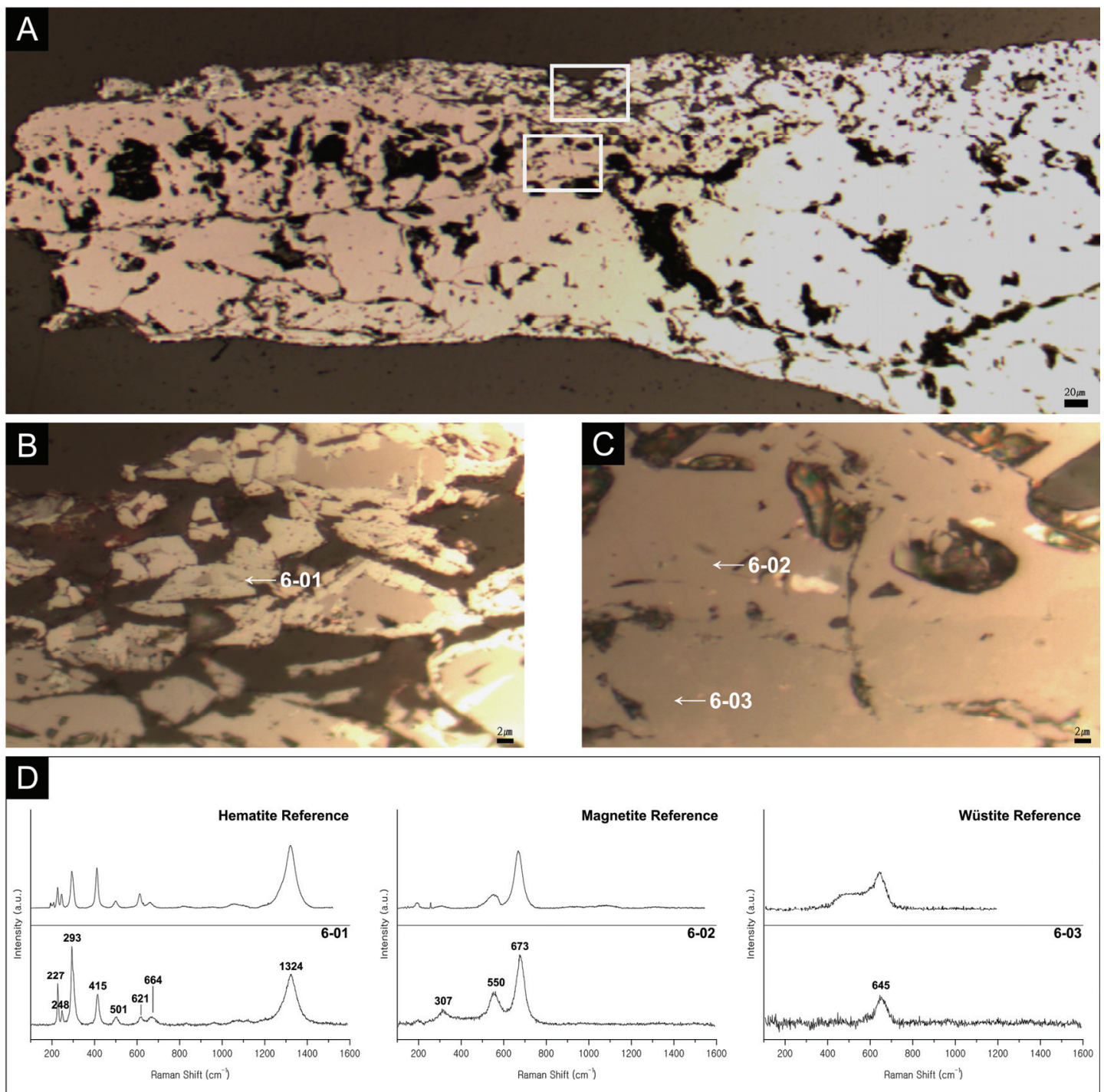

Figure 8. Raman micro-spectroscopy analysis results of No. 6 Flake Hammer Scale; (A) Analysis position. (B) Image of area in which the spectrum 6-01. (C) Image of area in which the spectrum 6-02 and 6-03. (D) Raman spectrum. 
together with spheroid hammer scale (Jungwon National Research Institute of Cultural Heritage, 2016). In the initial stage of the work, i.e., initial forging process, the wüstite of the inner layer exists as dendritic forms. However, in the later stage, i.e., molding process, dendritic wüstite aggregates through repeated forging to form a compressed flat shape. In addition, the surface was covered with an oxide layer and a flat shape was observed with a light-colored matrix structure inside. It can be inferred that the later stage of forging work progressed (Figure 6F). SEM-EDS analysis was performed to observe the detailed microstructures of flake hammer scales (Table 3, Figure 7F). As a result of the SEM-EDS analysis, 601 and 602 showed similar $\mathrm{FeO}$ contents of $98.54 \mathrm{wt} \%$ and $100.00 \mathrm{wt} \%$. Raman micro-spectroscopy was performed to accurately identify the microstructures of similar compositions. As a result of the metal microscope observation, inner layers were not distinguishable; however, Raman micro-spectroscopy revealed a difference in brightness between the surface and inside (Figure 8). The flake hammer scale, i.e., a derivative of granular materials, is related to smithing work. It consists of three layers: hematite in the surface layer, magnetite in the middle layer, and wüstite in the inner layer (Osawa, 2005).

In the microstructure 6-01, Raman shifts of 227, 248, 293, $415,501,621,664$, and $1324 \mathrm{~cm}^{-1}$ were detected, which were almost identical to those of hematite and their peak shapes were also similar (RRUFF, 2022); thus, it was identified as hematite $\left(\mathrm{Fe}_{2} \mathrm{O}_{4}\right)$. In the microstructure 6-02, Raman shifts of 307,550 , and $673 \mathrm{~cm}^{-1}$ were detected, which were almost identical to those of magnetite and their peak shapes were also similar (RRUFF, 2022); thus, it was identified as magnetite $\left(\mathrm{Fe}_{3} \mathrm{O}_{4}\right)$. In the microstructure 6-03, the Raman shift of $645 \mathrm{~cm}^{-1}$ was detected, which was almost identical to that of wüstite and their peak shapes were also similar (Park et al., 2019); thus, it was identified as wüstite (FeO). It is estimated the surface reacted with oxygen relatively more in the cooling process.

\section{DISCUSSION AND CONCLUSION}

The iron-making process was investigated through the scientific analysis of six samples, including slags, flake hammer scale, and spheroid hammer scale, excavated from the Songdu-ri site in Jincheon. The total Fe content of slag excavated from the Songdu-ri site was 36.29 54.61 wt $\%$ and the slag former content was $26.48 \sim 49.08 \mathrm{wt} \%$. When the total $\mathrm{Fe}$ content and deoxidation agent content according to smelting classification were examined based on the analysis of domestic iron-making sites, the total $\mathrm{Fe}$ content of direct smelting was 18.09 49.34 wt\%, and the deoxidation agent content was 30.10 49.14 wt\%. The extrusion temperature of by-products was obtained by substituting the analysis data in the FAS and FCS phase diagrams, and the temperature was mainly distributed around $1200^{\circ} \mathrm{C}$. In the case of direct smelting, iron can be obtained by reducing ores at temperatures below $1200^{\circ} \mathrm{C}$ (Rho, 2000). This suggests that the Songdu-ri site in Jincheon is a direct smelting site.

Furnaces no. 1 and 2 at location 1-2 and furnace no. 3 at location 1-4 were smelting and smithing hearths, where flake hammer scale and spheroid hammer scale were found. Fayalite and wüstite were detected as the main compounds of the slags excavated from here (No. 1 and 3), and the microstructure and component analysis indicated that the wüstite content was higher and the microstructure was coarser than those of other slag samples. This shows the characteristics of the slag formed in the smithing work.

In the slags (No. 4 and 5) excavated from furnace no. 13 at location 3-5 and furnace no. 14 at location 4-1, fayalite was detected as a major phase, and wüstite was observed in some samples. Through microstructure and component analysis, a glassy background and fayalite were identified, and wüstite was distributed on them. This suggests that these slags were produced through a smelting process.

If processes such as crushing, dressing, and calcination of iron ores before smelting enters the pretreatment stage of raw materials, it can be considered that the full-scale iron-making process started with smelting (Lee et al., 2017). From the technical aspect of the process, it can be classified into two stages of smelting and smithing; however, the smithing process can be subdivided for processing into four steps: smelting, refining, tempering, and forming (Lee et al., 2017). The tempering-smithing process is a type of forming and forging operations for making tools. In the temperingsmithing process, which is a tool and weapon forming process using iron materials obtained through refining, oxide scales are generated with the progress of heating and hammering operations, and they scatter around the work area. 
These scattering thin scales are called "Flake hammer scale" in archaeological terms (Song and Woo, 2012). The forging-forming work is divided into first and second stages, which can be verified by the microstructure shape of wüstite. In the first stage of the hammering work, which is an initial forging process, hammer scales are scattered, while the wüstite in the inner layer maintains a leaf shape. In the second stage of the hammering work, as the tool molding progresses, the wüstite grains in the form of the first leaves of the inner layer agglomerate by forging to form a compressed flat shape due to repeated forging (Song and Woo, 2012). In the flake hammer scale of No. 6, a flat shape with a bright matrix structure was observed. From this, it can be inferred that the forging work progressed to the second stage.

As derivatives of spheroid hammer scale, flake hammer scale is related to smithing work, and the inside is composed of three layers: hematite, magnetite, and wüstite (Osawa, 2005). For the No. 6 flake hammer scale, differences in brightness between the surface and inside could be identified through Raman micro-spectroscopy. The surface was identified as hematite $\left(\mathrm{Fe}_{2} \mathrm{O}_{4}\right)$, middle layer as magnetite $\left(\mathrm{Fe}_{3} \mathrm{O}_{4}\right)$, and inner layer as wüstite $(\mathrm{FeO})$.

Identification of smelting and smithing slags, smelting and smithing hearths, spheroid hammer scale, and flake hammer scale at the Songdu-ri site in Jincheon suggests that it is a site where iron blooms were produced through division of labor for direct smelting, followed by refining and forge welding process, and then the iron-making process to produce ingots. This study verified the iron-making process and technical system through the analyses of iron-making by-products from the Songdu-ri site. If the research on by-products obtained during iron-making process in Jincheon and other various regions continues in the future, it is expected to assist in the research of the iron-making culture in the Jungwon region.

\section{ACKNOWLEDGMENTS}

This study was supported by the Protection Research Support Project among the basic research projects in science and engineering field of the Korea Research Foundation with funding from the government (Ministry of Education) in 2020 (NRF-2020R1I1A2072253).

\section{REFERENCES}

Bae, C.R., 2018, Study on the iron production process through the analysis of by-products excavated from iron smelting site in Bupyeong-ri, Inje, Korea. Master's dissertation, Kongju National University, Gongju. (in Korean with English abstract)

Bae, C.R. and Cho, N.C., 2020, A study of the iron production process through the analysis of slags excavated from Bupyeong-ri, Inje, Korea. Journal of Conservation Science, 36(2), 143-151. (in Korea with English abstract)

Central Institute of Cultural Heritage, 2020, Songdu-ri site, Jincheon. 5, 1-579. (in Korean)

Cho, H.K., 2015, Manufacturing technology of iron swords in the Midwestern Korea from 2nd to 6th century AD. Ph.D. dissertation, Kongju University, Gongju. (in Korean with English abstract)

Cho, H.K., Cho, N.C. and Kang, D.I., 2013, Scientific analysis of slags and furnace wall collected from iron production site at Suryong-ri Wonmorongi in Chungju. Journal of Conservation Science, 29(2), 139-147. (in Korea with English abstract)

Choi, K.J., 2003, Achaeometallurgical study on the manufacturing of iron and bronze artifacts. Ph.D. dissertation, Hongik University, Seoul. (in Korean with English abstract)

Jungwon National Research Institute of Cultural Heritage, 2014, Scientific analysis report on the specimens excavated from archaeological iron sites in Jungwon region. 1-183. (in Korea with English abstract)

Jungwon National Research Institute of Cultural Heritage, 2016, Scientific analysis report on the specimens excavated from archaeological iron sites in Gyeongsang region. 1-183. (in Korea with English abstract)

Kwon, I.C., 2016, Study of microcrystals of iron sand smelting slag per $\mathrm{TiO}_{2}$ content using Raman microspectroscopy. Master's dissertation, Kongju National University, Gongju. (in Korean with English abstract)

Lee, E.W., Kwak, B.M., Kim, E.J., Han, Y.W. and Park, C.L., 2017, Study on the restoration of ancient smelting and smithing technologies in the Jungwon area. Journal of Conservation Science, 33(6), 519-532. (in Korea with English abstract)

Lee, E.W., Kwak, B.M., Kim, E.J. and Park, J.R., 2018, Experiment on the ancient smelting-smithing technologies - A study on the proper experimental temperature -. Journal of Conservation Science, 34(6), 581-593. (in Korea with English abstract) 
Lee, Y.N., 2017, Metallurgical study on the by-products of the iron smelting excavated from Jinwi region in Pyeongtaek. Master's thesis, Kongju National University, Gongju. (in Korean with English abstract)

National Museum of Korea., 2017, Metal, iron and steel; The cultural history of iron. 1-271. (in Korea with English abstract)

Osawa, M., 2005, Metallurgical study of the forging artifacts excavated from Wolseong-Dong. Korea Cultural Heritage Foundation, 177.

Park, S.K., Kwon, I.C., Lee, S.J., Huh, I.K. and Cho, N.C., 2019, Microstructural analysis of slags using Raman micro spectroscope. Journal of Conservation Science, 35(2), 145-152. (in English)

Rho, T.C., 2000, A historic study on the ancient metallurgical technology in Korea. Hakyounmunhwasa, Seoul. (in Korean)

RRUFF, 2022, Hematite. https://rruff.info/hematite/display= default/R050300 (January 25, 2022)

RRUFF, 2022, Magnetite. https://ruff.info/magnetite/ display $=$ default/R060191 (January 25, 2022)

Song, J.I. and Woo, K.D., 2012, Forging process process technology as observed in the microstructure of a hammer scale excavated from the Naju Bogam-ri remains. Korean Journal of Metals and Materials, 50(8), 599-603. (in Korea with English abstract)

Yoon, D.S., 1986, On the slag produced in early iron metallurgy. The Journal of the National Academy of Science, 25, 380-390. (in Korean with English abstract) 